Article

\title{
Investigation of the Effect of Structural Properties of a Vertically Standing CNT Cold Cathode on Electron Beam Brightness and Resolution of Secondary Electron Images
}

\author{
Ha Rim Lee ${ }^{1,2}$, Da Woon Kim ${ }^{1}$, Alfi Rodiansyah ${ }^{1}$, Boklae Cho ${ }^{2}$, Joonwon Lim ${ }^{1, *}$ and Kyu Chang Park ${ }^{1, *}$ \\ 1 Department of Information Display, Kyung Hee University, Dongdaemun-gu, Seoul 024471, Korea; \\ hrim@khu.ac.kr (H.R.L.); dawoon0601@khu.ac.kr (D.W.K.); rodiansyahalfi@khu.ac.kr (A.R.) \\ 2 Advanced Instrumentation Institute, Korea Research Institute of Standards and Science (KRISS), \\ 267 Gajeong-ro, Yuseong-gu, Daejeon 34113, Korea; blcho@kriss.re.kr \\ * Correspondence: joonwon.lim@khu.ac.kr (J.L.); kyupark@khu.ac.kr (K.C.P.)
}

Citation: Lee, H.R.; Kim, D.W.; Rodiansyah, A.; Cho, B.; Lim, J.; Park, K.C. Investigation of the Effect of Structural Properties of a Vertically Standing CNT Cold Cathode on

Electron Beam Brightness and Resolution of Secondary Electron Images. Nanomaterials 2021, 11, 1918. https://doi.org/10.3390/ nano11081918

Academic Editors: Jakob Birkedal Wagner and Jun Chen

Received: 10 June 2021

Accepted: 23 July 2021

Published: 26 July 2021

Publisher's Note: MDPI stays neutral with regard to jurisdictional claims in published maps and institutional affiliations.

Copyright: (c) 2021 by the authors. Licensee MDPI, Basel, Switzerland. This article is an open access article distributed under the terms and conditions of the Creative Commons Attribution (CC BY) license (https:/ / creativecommons.org/licenses/by/ $4.0 /)$.

\begin{abstract}
Carbon nanotube (CNT)-based cold cathodes are promising sources of field emission electrons for advanced electron devices, particularly for ultra-high-resolution imaging systems, due to their high brightness and low energy spread. While the electron field emission properties of single-tip CNT cathodes have been intensively studied in the last few decades, a systematic study of the influencing factors on the electron beam properties of CNT cold cathodes and the resolution of the secondary electron images has been overlooked in this field. Here, we have systematically investigated the effect of the structural properties of a CNT cold cathode on the electron beam properties and resolution of secondary electron microscope (SEM) images. The aspect ratio (geometric factor) and the diameter of the tip of a vertically standing CNT cold cathode significantly affect the electron beam properties, including the beam size and brightness, and consequently determine the resolution of the secondary electron images obtained by SEM systems equipped with a CNT cold cathode module. Theoretical simulation elucidated the dependence of the structural features of CNT cold cathodes and electron beam properties on the contribution of edge-emitted electrons to the total field emission current. Investigating the correlations between the structural properties of CNT cold cathodes, the properties of the emitted electron beams, and the resolution of the secondary electron images captured by SEM equipped with CNT cold cathode modules is highly important and informative as a basic model.
\end{abstract}

Keywords: carbon nanotube; field emission; electron beam; electron microscope

\section{Introduction}

Field emission electron sources have attracted enormous research attention in the field of electron emission and electron devices, due to their inherent merits, including high brightness, coherence, and low energy spread [1-5]. Owing to those advantages, distinguished from conventional thermionic electron sources, field emission electron sources, i.e., cold cathodes, have been considered as a promising component for advanced microscope systems, enabling ultra-high-resolution imaging at the nano- or atomic scales [6-8]. As the best choice for cold cathode materials, carbon nanotubes (CNTs) have drawn much research attention due to their highly efficient electron field emission properties, originating from the synergistic effect of high electrical conductivity and high aspect ratio [9-14]. Especially, the small radius of curvature of the tip of CNT cold cathodes induces a substantial field enhancement effect and decreases the operating voltage of the field emission devices. It is beneficial for a miniaturized electron emission source to be able to be driven stably up to few micro-amperes of current [15-20]. Moreover, mature CNT synthesis techniques have achieved uniform large areal arrays and site-selective vertically aligned structures. Despite the suitable features of CNTs for high-performance cold cathodes, there 
have been difficulties in realizing CNT cold cathodes for ultra-high-resolution microscope systems due to the lack of a systematic study on the correlation between the imaging resolution and the properties of electron beams emitted by such cathodes.

Ultra-high-resolution imaging systems using electron beams require two vital conditions: high electron emission current and small enough probe size [21]. In this regard, it is necessary to investigate the electron emission current and electron probe size of electron beams generated from CNT cold cathodes in order to realize CNT cold cathode-based ultra-high-resolution imaging systems. It is especially important and valuable to study vertically aligned individual CNT cold cathodes as a basic model to develop sophisticated CNT cold cathodes. Even though a CNT cold cathode effectively enhances the electric field at the tip of the one-strand electron field emitter by removing the screening effect, it is usually unstable with high field emission current value or long-term electron emission [22] This leads to a lack of systematic and reliable studies on the electron emission current and probe size of individual CNT emitters. Moreover, precise control of the location and reproducible shape engineering of CNT cold cathode are also required to guarantee reliability.

In this work, we studied the effects of the structural properties of CNT cold cathodes on the electron beam properties and the resolution of secondary electron images. CNT cold cathodes were grown on silicon substrates via plasma-enhanced chemical vapor deposition (PECVD) with patterned Ni catalysts, offering precise control of the location of vertically aligned CNTs. The aspect ratio and the tip diameter of the CNT cold cathode significantly affects the diameter and brightness of the electron beam. CNT cold cathodes show high field emission current, high beam brightness, and small beam diameter with increasing aspect ratio (high geometric factor, $\beta_{\text {geo }}$ ) and decreasing tip diameter. In theoretical study, a simulated electron trajectory consistent with empirical results indicates that the $\beta_{\text {geo }}$ and the tip diameter of the CNT dominate the size and areal uniformity of the resultant electron beam. Consequently, the resolution of images obtained with a CNT cold cathode module mounted in a scanning electron microscope (SEM) system improves with high $\beta_{\text {geo }}$ and small tip diameter.

\section{Materials and Methods}

The used CNT cold cathode was composed of a vertically standing, one-strand and cone-shaped CNTs grown on a highly doped n-type silicon (100) substrate. The location of a CNT cold cathode was controlled to be in the center of the Si substrate, cut into a $4 \times 4 \mathrm{~mm}^{2}$ piece. The structure of the emitters was determined by the growing conditions. A nickel dot, 3-5 $\mu \mathrm{m}$ in diameter and fabricated by a conventional photolithography process, determined the position of the CNT cold cathode. The advantage of CNT field emitters is that the number of emitters can be precisely adjusted, allowing control of the electron emission current value by adjusting the number of CNT field emitters [23].

The location of the CNT cold cathode on the Si substrate was controlled by the predetermined locations of $20 \mathrm{~nm}$-thick Ni catalysts, using a photolithography technique. The prepared $\mathrm{Ni}$ patterns were annealed to produce seeds for the growth of CNTs [24,25]. The CNT cold cathodes were grown using a triode-type, direct current, plasma-enhanced chemical vapor deposition (DC-PECVD) system. The emitter grown by PECVD is characterized by a cone shape, as shown in Figure 1. The CNT cold cathodes grows from several nano-sized nickel grains and merges into one at the tip end [26]. After the forming process, CNTs are grown in the DC-PECVD system, and the emitter structure can be adjusted according to the growing conditions. Several parameters determine the structure of a CNT cold cathode: seed size, temperature, pressure, plasma current, and gas ratio [27]. These growing conditions are listed in Table 1. Under such conditions, we can grow CNTs by determining the range of $\beta_{\text {geo }}$ of CNT cold cathodes. 

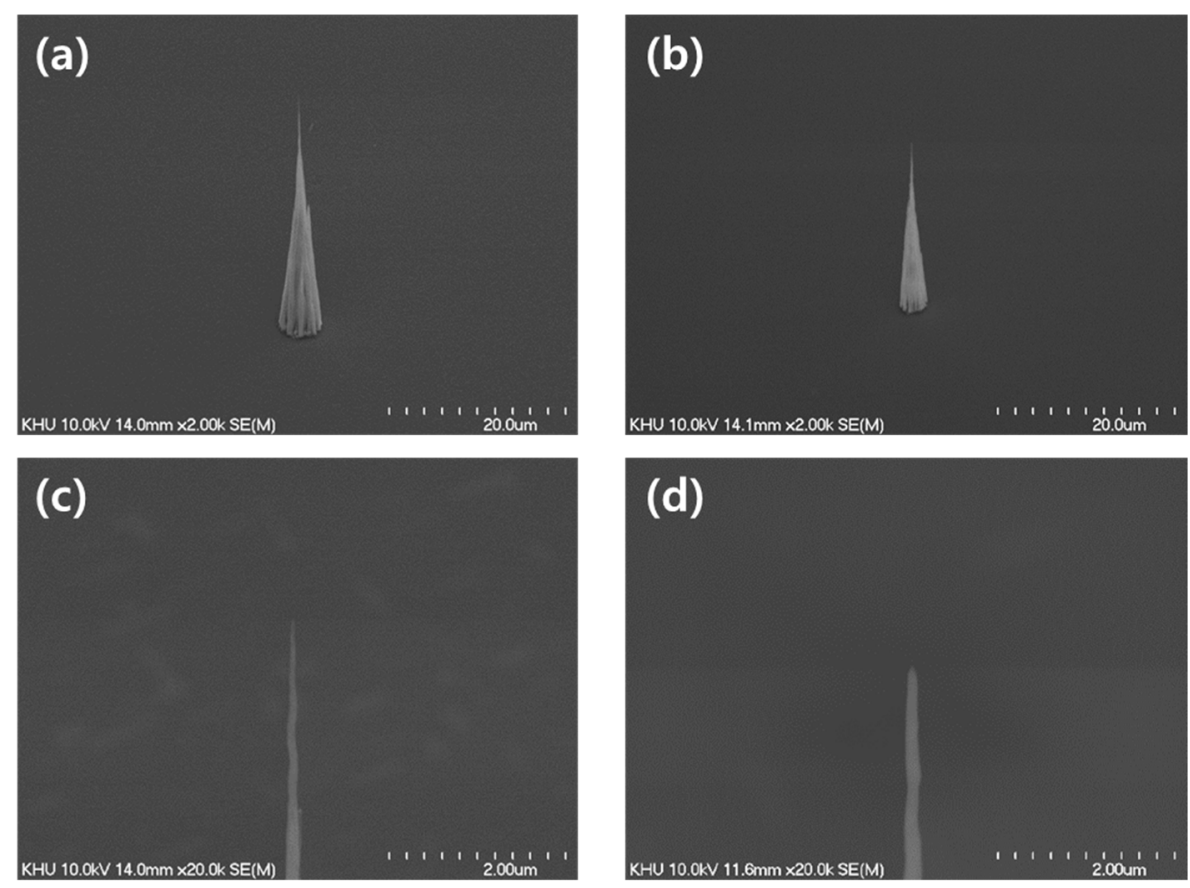

Figure 1. SEM images of CNT cold cathodes: (a) geometric factor 1560 (1560-CNT) and (b) 550-CNT cold cathode. (c) Magnified image of (a) at tip region; (d) magnified image of (b).

Table 1. Summary of carbon nanotube (CNT) growing conditions.

\begin{tabular}{cccccc}
\hline $\begin{array}{c}\text { Geometric } \\
\text { Factor }\end{array}$ & $\begin{array}{c}\mathrm{C}_{\mathbf{2}} \mathrm{H}_{\mathbf{2}}: \mathbf{N H}_{\mathbf{3}} \\
\text { (SCCM) }\end{array}$ & $\begin{array}{c}\text { Voltage (V) } \\
\text { (Grid/Substrate) }\end{array}$ & $\begin{array}{c}\text { Pressure } \\
\text { (Torr) }\end{array}$ & $\begin{array}{c}\text { Dot Size } \\
(\boldsymbol{\mu m})\end{array}$ & $\begin{array}{c}\text { Growing } \\
\text { Time (min) }\end{array}$ \\
\hline $2800-3500$ & $16: 160$ & $300 /-600$ & 2 & 3 & 100 \\
$600-1500$ & $16: 160$ & $300 /-600$ & 3 & 5 & 60 \\
$\sim 500$ & $16: 200$ & $300 /-600$ & 2.5 & 5 & 90 \\
\hline
\end{tabular}

Figure 1 shows scanning electron microscope (SEM) analysis of CNT cold cathodes

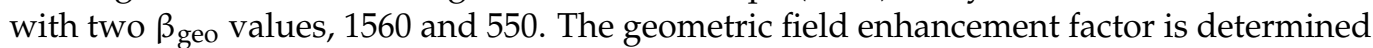
by the apex tip radius and height, and is defined as the height of the emitter divided by the radius of the tip [14,28]. A 1560 emitter has a height of $39 \mu \mathrm{m}$ and a tip radius of $25 \mathrm{~nm}$, and a 550 emitter has a height and radius of $27.5 \mu \mathrm{m}$ and $75 \mathrm{~nm}$. Based on those parameters, we modeled the SOURCE 2D simulation (Munro's Electron Beam Software, London, UK) to analyze the characteristics of the trajectory, the emission current, and the brightness of the electron beam. The SOURCE 2D simulation was calculated, taking into account the space charge effect using the second order finite element method [29].

The evaluation of the electron emission properties was conducted in diode mode, with a homemade phosphor screen, under high vacuum level $\left(<10^{-7}\right.$ torr $)$. We carried out comparative analyses of the electron emission characteristics and emission patterns in the diode structure with several $\beta_{\text {geo }}$ values. The distance from CNT cold cathode to anode was $250 \mu \mathrm{m}$.

To observe the structure of CNT cold cathodes, SEM analysis was conducted (Hitachi S-4700). We used a DC power supply (Spellman SL1200, Keithley 248) and multimeter (Agilent 34401A, Keithely 6485) to measure the field emission characteristics. The electron emission characteristics were analyzed using the Fowler-Nordheim (F-N) theory. The electron emission pattern was observed by optical microscope.

\section{Results and Discussion}

The basic field emission characteristics were measured in the diode structure with the phosphor anode for evaluation of the CNT cold cathode. Figure $2 \mathrm{a}, \mathrm{b}$ show comparisons 
of the field emission characteristics and FN plots according to $\beta_{\text {geo }}$ values, respectively. The CNT field emitters with $\beta_{\text {geo }}$ values of 1560 and 550 showed $1 \mu \mathrm{A}$ of emission current at 950 and $2250 \mathrm{~V}$, respectively. The slope of the FN plot of the $1560 \mathrm{CNT}$ cold cathode was -35006 , and the slope of the 560 was -48725 in the linear region of Figure $2 b$. The CNT emitter with high $\beta_{\text {geo }}$ showed high emission current at lower voltages. The difference in the field emission properties is attributed to the lower threshold voltage at the edge of the emitter tip. It indicates that the enhancement of the applied electrical field is facilitated by the CNT with small tip size, compared with the CNT with large tip size. Also, the height of the emitter itself is an important parameter. Therefore, many studies refer to a high aspect ratio $\left(\beta_{\text {geo }}\right)$ as a very important variable. Figure $2 c$ shows a comparison of electron emission patterns at a current of $1 \mu \mathrm{A}$. The CNT field emitters with $\beta_{\text {geo }}$ values of 1560 and 550 show $55 \mu \mathrm{m}$ of the beam size at $950 \mathrm{~V}$ and $114 \mu \mathrm{m}$ at $2250 \mathrm{~V}$, respectively.

(a)

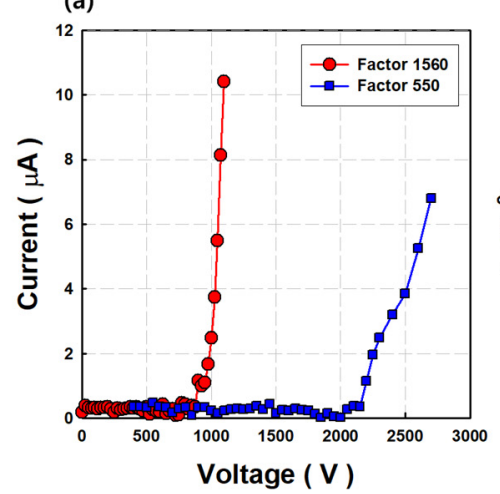

(b)

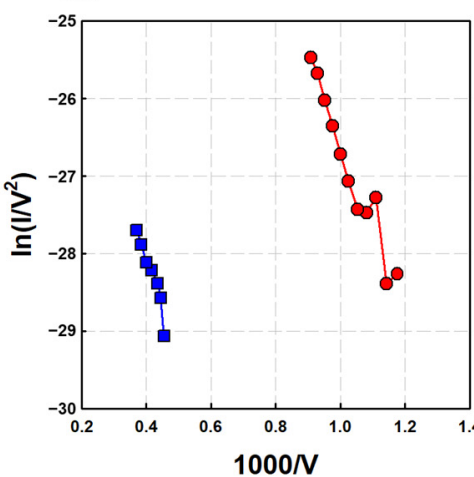

(c)

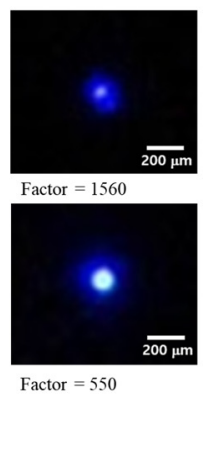

Figure 2. Comparison of field emission properties. (a) Field emission properties; (b) F-N plot; (c) captured image of field emission patterns on phosphor screen at $1 \mu \mathrm{A}$ of emission current.

The source of electrons for an electron microscope can be evaluated by characterizing simple electron emission, including the solid angle, the virtual source size, and the brightness of the electron beam. In our previous study, we studied reduced brightness $\left(B_{r}\right)$ calculation using electron emission patterns to evaluate CNT cold cathodes [30]. $B_{r}$ measures the spot size and the amount of emission current that can be concentrated at a particular solid angle. It is a function of the virtual radius source size, the brightest part of the emitted electron beam, and the current densities corresponding to the beam potential [31]. The virtual source radius is the area where electrons are generated. The high brightness means that the electrons are emitted at a narrow solid angle, the size of the starting beam trajectory is small, and there is a large amount of emission current at low voltage. Thus, $\mathrm{B}_{\mathrm{r}}$ is expressed by the following equation [32], where $J_{\Omega}$ is the angular current density and $r_{v}$ is the virtual source radius:

$$
B_{r}=\frac{J_{\Omega}}{\pi r_{v}^{2} V} .
$$

The electron beam pattern was observed by optical microscope and was measured with an image analysis tool to obtain the correct beam size. Beam size values of $55 \mu \mathrm{m}$ and $114 \mu \mathrm{m}$ were obtained from the full width at half maximum (FWHM) value at the bright spot using Gaussian four-peak parameter fitting [33]. As a result of emission patterns, the solid angles of 1560- and 550-CNT emitters were 0.053 and $0.2 \mathrm{sr}$, respectively, at an emission current of $1 \mu \mathrm{A}$. To calculate the virtual source radius, we refer to Fowler-Nordheim (F-N) theory, which understands the field emission phenomenon mathematically. Its emission current $(J)$ density is as follows [34]:

$$
J=1.54 \times 10^{-6} \frac{F^{2}}{\varnothing} \exp \left(-6.83 \times 10^{-7} \frac{\varnothing^{3 / 2}}{F}\right)
$$




$$
\begin{gathered}
F=\beta V \\
\beta_{\text {geo }}=m+h / R
\end{gathered}
$$

where $F$ and $\varnothing$ are the local electric field and the work function in electron volts, respectively. $R$ is the radius of curvature, $h$ is the height of the emitter, and $m$ is a variously taken constant of 0,2 , or 3 ; $m$ converges to 0 if the height of the emitter is considerably greater than the curvature radius $(h>>R)$. This $\beta_{\text {geo }}$ calculation method was first proposed by Vibrans (1964) [35]. As indicated in the F-N equation, two parameters affect the field emission properties of a field emitter. The work function of CNTs is widely known to be $5 \mathrm{eV}[36,37]$. These two variable values are reflected in the tunneling parameters $(d)$ and are important factors in calculating the virtual source radius [38]:

$$
\begin{gathered}
d=1.54 \times 10^{-6} \frac{e h F}{4 \pi \sqrt{2 m \varnothing} \times t(y)} \\
t(y)=1+0.1107 y^{1.33} \\
r_{v}=\sqrt{\frac{3 R d}{e k F}}
\end{gathered}
$$

where $t(y)$ and $y$ are slowly varying functions of $F$ and $\varnothing$ [39]. The electric field applied to the CNT cold cathode depends on the structure of the emitter $\left(\beta_{\text {geo }}\right)$. The tunneling parameters of the CNT emitter range from 0.1 to $0.3 \mathrm{eV}$. The $r_{v}$ of the spherical cap structure is determined by $d$, the physical source diameter of field emitter and the local electric field, and $k$ is the field enhancement related factor, which frequently takes a value of five [40]. The physical source diameter $(R)$ of the CNT cold cathode was 50 and $150 \mathrm{~nm}$, as shown in Figure 1, and we could calculate that $r_{v}$ was 0.8 and $1.3 \mathrm{~nm}$ for the CNT cold cathode, respectively. As a result, the theoretical angular current density of the 1560- CNT cold cathode was $20.89 \mu \mathrm{A} \cdot \mathrm{sr}^{-1}$ and $B_{r}$ was $1.08 \times 10^{10} \mathrm{~A} \cdot \mathrm{m}^{-2} \cdot \mathrm{sr}^{-1} \cdot \mathrm{V}^{-1}$ at an applied voltage of $950 \mathrm{~V}$. For the 550 - CNT cold cathode, $B_{r}$ was $3.7 \times 10^{8} \mathrm{~A} \cdot \mathrm{m}^{-2} \cdot \mathrm{sr}^{-1} \cdot \mathrm{V}^{-1}$ at an applied voltage of $2250 \mathrm{~V}$ and the angular current density was $5.09 \mu \mathrm{A} \cdot \mathrm{sr}^{-1}$. The smaller the value of $\beta_{\text {geo }}$, the higher the required driving voltage, resulting in a larger beam diameter and wide angular current density.

SOURCE 2D simulation is a useful tool with which to analyze and design electron sources. This tool is available for all types of electron sources, from point cold cathodes to high-current piercing. The simulation study calculates the space charge distribution based on the Poisson equation, and electron trajectories are computed by direct ray tracing [28]. Figure 3a,b shows the beam trajectories of the CNT cold cathodes with 1560 and $550 \beta_{\text {geo. }}$ The figure inset images show the computed electron emission at the tip region. The basic variable parameters are set to the same values, including CNT work function, energy spread, and temperature. The comparative simulation results are highly dependent on the structure of the field emitter. Based on the measured field emission characteristics, the trajectory and beam brightness were computed at an emission current of $1 \mu \mathrm{A}$. The distance between source plane and anode was $200 \mu \mathrm{m}$ and the maximum beam size was $258 \mu \mathrm{m}$ (Figure 3a) and $381 \mu \mathrm{m}$ (Figure 3b), respectively. Figure 3c shows the computed I-V curve based on the experimental values. The SOURCE 2D simulation is computed for the launch point of electron emission at the tip region, which is named the maximum half arc length, as shown in Figure 3d (dashed black line in the first image). The maximum half arc length of the 1560- CNT cold cathode was $48 \mathrm{~nm}$, and the current density at the apex of the tip was the highest, calculated as $1.1 \times 10^{4} \mathrm{~A} \cdot \mathrm{cm}^{-2}$. For the 550 emitter, the maximum half arc length was $110 \mathrm{~nm}$ and the current density at the edge of the tip was the highest. Figure $3 d$ shows the beam trajectory and emission current density at the CNT tip with various diameters. As the tip diameter increased, the current density at the edge region was enhanced. This indicates that a small-sized CNT tip is highly beneficial to obtain a well-focused and high-density electron beam. 
(a)

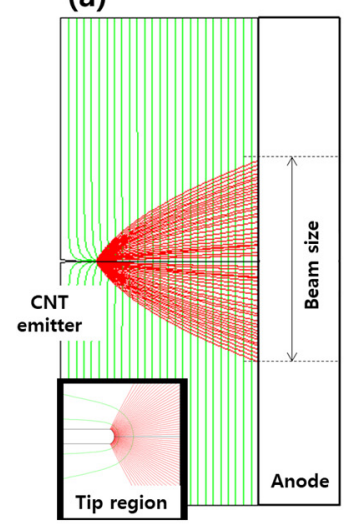

(d)
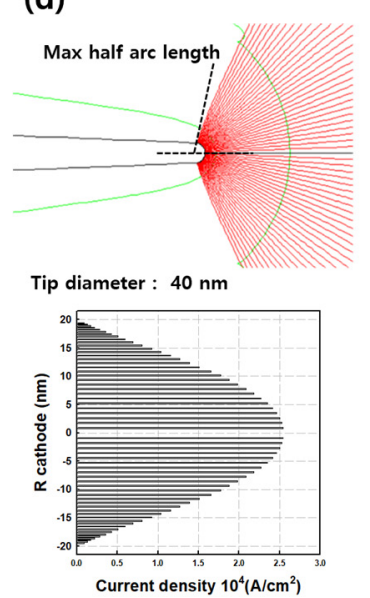

(b)

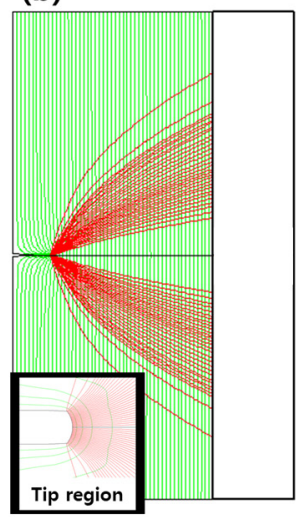

(c)

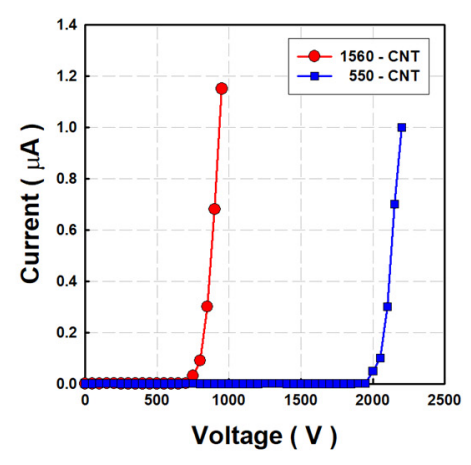

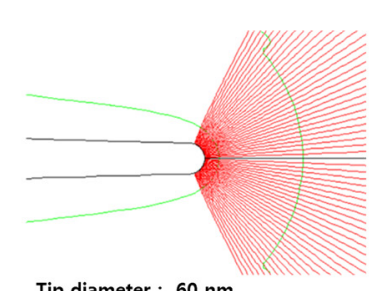

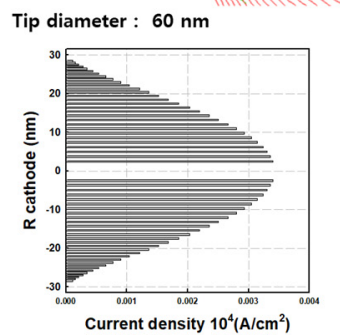

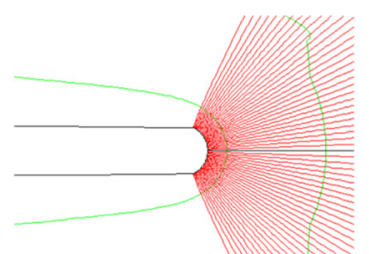

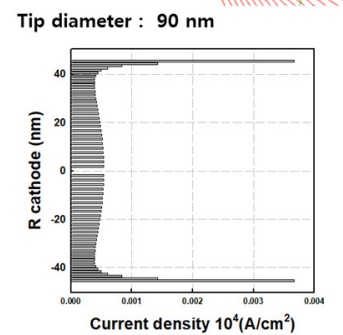

Figure 3. SOURCE 2D simulation results. (a) The CNT cold cathode with a geometric factor of 1560. (b) The CNT cold cathodes with a geometric factor of 550. (c) Comparison of simulated I-V curve. (d) Emission current density at tip region with tip diameter.

We evaluated the electron emission characteristics and designed an optimized electron beam module based on the protocol reported in our previous study [29]. The CNT cold cathode was applied to an electron microscope imaging device as an electron source. Figure 4a shows the configuration of the system for secondary electron imaging. Typical SEM systems are composed of an electron source, two condenser lenses (CLs), an objective lens (OBJ), and a stage for a sample in a vacuum chamber. The CL serves to demagnify the electron beam and determines the probe size and resolution. The OBJ serves to adjust the working distance. The distance between the electron gun part and OBJ is $400 \mathrm{~mm}$ and working distance is $2 \mathrm{~mm}$. Figure $4 \mathrm{~b}$ shows a schematic illustration and real optical image of the electron beam module with a CNT cold cathode. As shown in real optical images in Figure 4c, the electron beam module consists of CNT cold cathode on the cathode and a mesh-type gate electrode with holes $300 \mu \mathrm{m}$ in diameter where the CNT cold cathodes are precisely aligned at the center of the aperture. The distance between the gate electrode and the cathode was adjusted to $250 \mu \mathrm{m}$, and the anode of the SEM system was located $8 \mathrm{~mm}$ below. The lens units and the sample stage in the chamber were connected to the ground. Thus, the electron beam was driven in the range of negative voltage. A wobbling process is generally required to minimize CL aberration, in order to obtain high-resolution images. For precise evaluation of the electron beam characteristics of each CNT cold cathode, secondary electron imaging was carried out with only the as-emitted electron beam from the CNT cold cathode and all CLs turned off. 
(a)

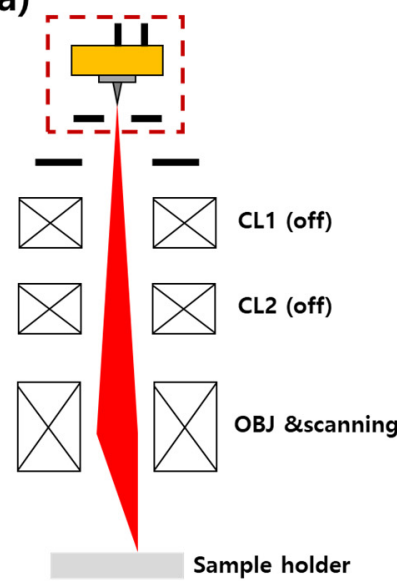

(b)

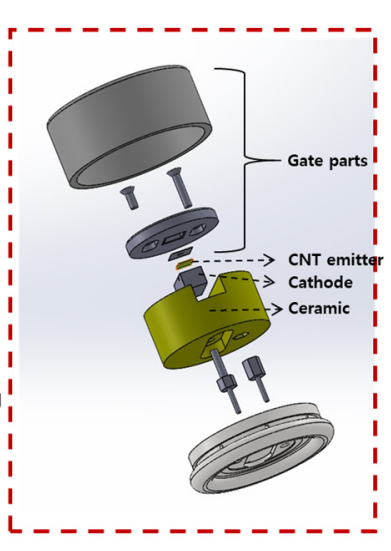

(c)

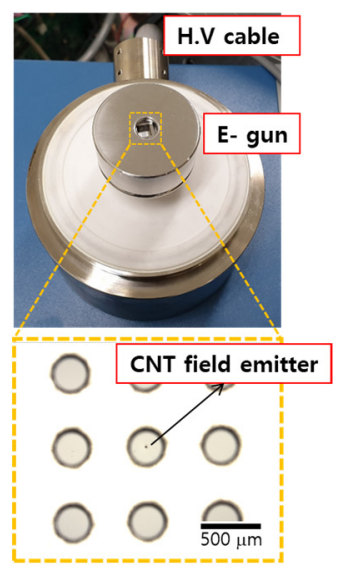

Figure 4. (a) Schematic diagram of normal SEM equipment with single CNT emission gun. (b) CNT electron gun cartridge. (c) Captured image of gun part and alignment with gate electrode and single CNT emitter.

Figure 5a-d shows scanning secondary electron images of copper $(\mathrm{Cu})$ mesh grids (2000) captured during the aging process, obtained by the CNT cold cathode. All SEM images were measured without the CL operation. The electrons were emitted at $10^{-8}$ torr at the gun part with acceleration voltage $\left(\mathrm{V}_{\mathrm{acc}}\right)$ of $5 \mathrm{kV}$. The resolution of the SEM image was improved with aging time. Figure 5 a shows the first image obtained at an emission current of $0.5 \mu \mathrm{A}$. The image shows an undesired alternating light and dark line, indicating that the emission current is unstable. Interestingly, the resolution and definition of the measured SEM image increased with aging time. Figure 5e shows the electrical aging process of the CNT cold cathode. The emitter had a $\beta_{\text {geo }}$ of 790 and the relative extraction voltage $(\Delta \mathrm{V})$ was $900 \mathrm{~V}$. In the initial $6 \mathrm{~h}$, the average emission current was $0.5 \mu \mathrm{A}$ in constant voltage mode $(\Delta \mathrm{V}=900 \mathrm{~V})$, and the current fluctuation was $25 \%$. After $10 \mathrm{~h}$, the average emission current increased to $1 \mu \mathrm{A}$, and the current stability was shown to be $15 \%$, which was more stable than the initial one. The stabilized electron emission current yielded improved images, as shown in Figure 5d. It is rationalized with the recovery of defect sites in the CNT cold cathode. After the electrical aging process, the ratio of defect peak to graphite peak increased in the Raman result [41].

(a)

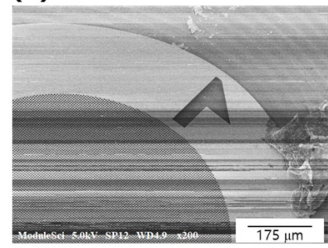

(c)

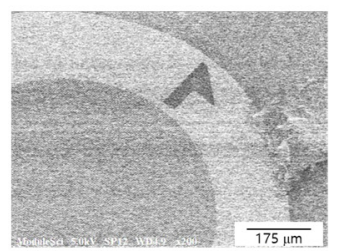

(b)

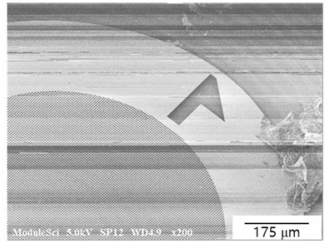

(d)

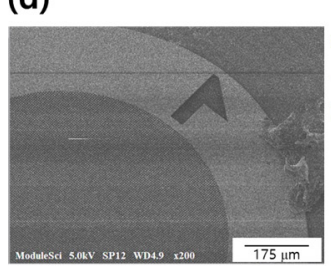

(e)

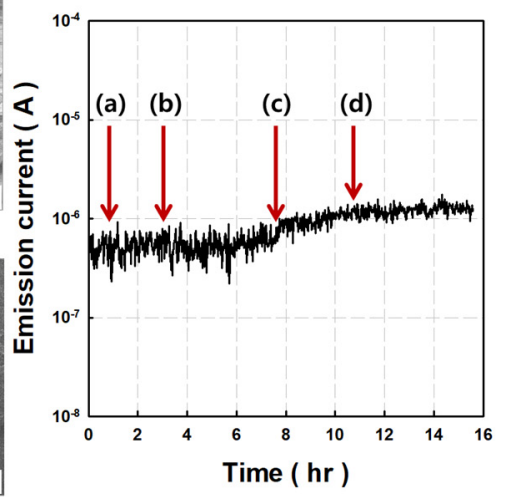

Figure 5. Scanning secondary electron image with CNT cold cathode gun. (a-d) SEM images of Cu grid mesh (2000) during aging process. (e) Electron emission current stability in constant voltage mode $(\Delta \mathrm{V}=900 \mathrm{~V})\left(\Delta \mathrm{V}=\mathrm{V}_{\mathrm{acc}}-\mathrm{V}_{\mathrm{ex}}\right)$. 
Figure 6 shows SEM images obtained with the CNT cold cathodes with different

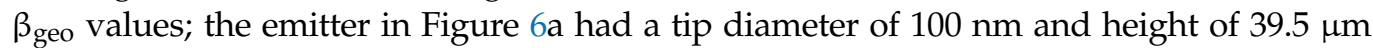
$\left(\beta_{\text {geo }}=790\right)$, and the one in Figure $6 \mathrm{~b}$ had a tip diameter of $50 \mathrm{~nm}$ and height of $28.9 \mu \mathrm{m}$ $\left(\beta_{\text {geo }}=1156\right)$. Figure 6(a-1-c-1) show SEM images obtained at an acceleration voltage of $5 \mathrm{kV}$ and $1 \mu \mathrm{A}$ of emission current. The SEM image in Figure $6 \mathrm{a}$ was obtained after the aging process. Figure $6(a-2)$ shows $1000 \times$ magnified SEM images of the region of the dashed square yellow line in Figure 6(a-1). Figure 6(b-1,b-2) shows SEM images obtained with the a CNT cold cathode in Figure $6 \mathrm{~b}$ under identical conditions as in Figure 6a. Figure 6c shows SEM images obtained with a CNT cold cathode with a tip diameter of $125 \mathrm{~nm}$ and height of $26.1 \mu \mathrm{m}\left(\beta_{\text {geo }}=417\right)$. Despite the higher emission current of $3 \mu \mathrm{A}$ than in the previous cases, the resulting SEM image was severely blurred, as shown in Figure 6(c-1). Even under three times higher emission current, a high-magnification image could not be properly obtained. This means that the beam brightness is low due to structural limitations.
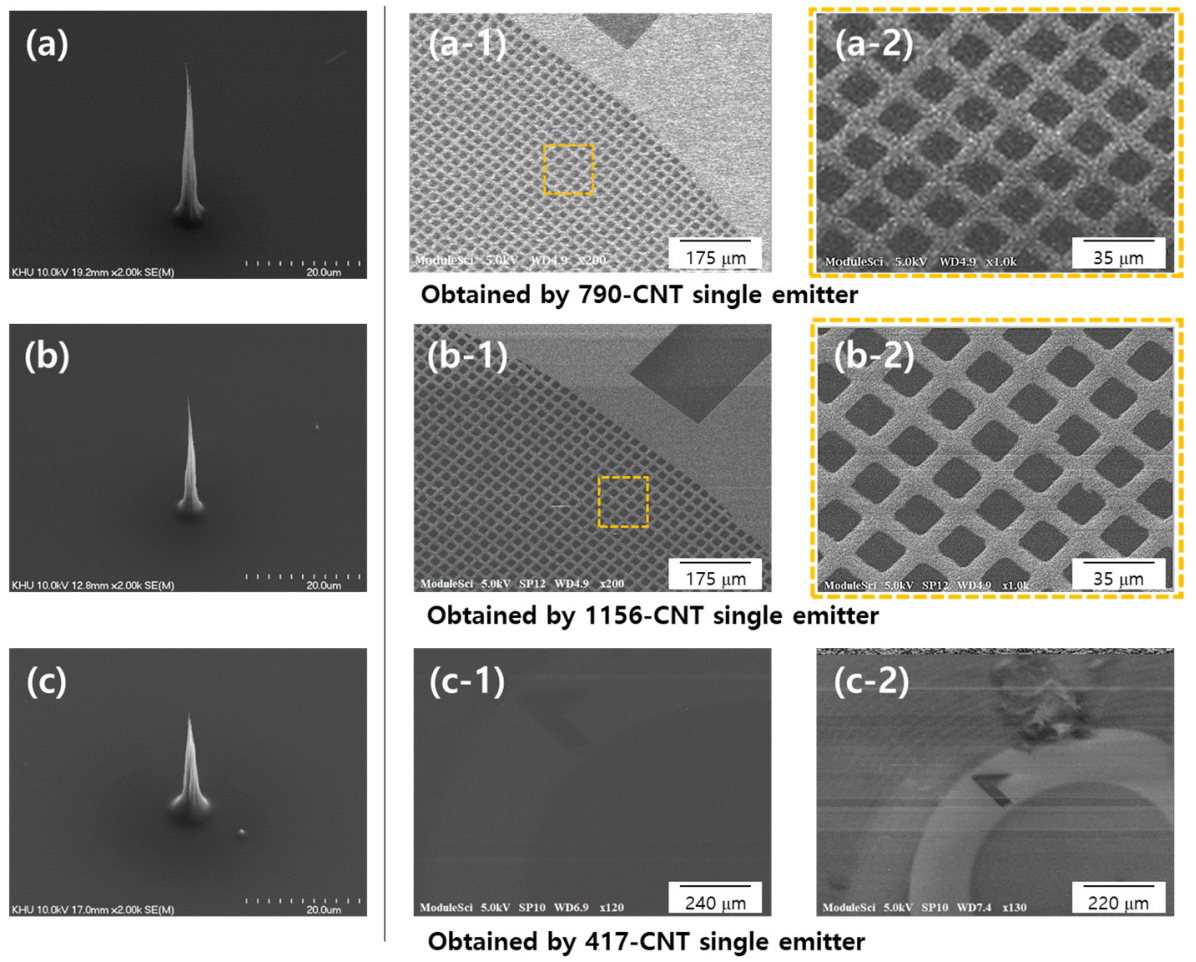

Figure 6. Comparison of scanning secondary electron images with structural properties of CNT cold cathodes. SEM images of a CNT cold cathode with: (a) $\beta_{\text {geo }}=790, \Delta \mathrm{V}=1200 \mathrm{~V}$; (b) $\beta_{\text {geo }}=1560$, $\Delta \mathrm{V}=900 \mathrm{~V}$; and (c) $\beta_{\text {geo }}=417, \Delta \mathrm{V}=2100 \mathrm{~V}$. (a-1-c-1) SEM images of Cu grid mesh (2000) at $5 \mathrm{kV}$ acceleration voltage and $1 \mathrm{~A}$ emission current. (a-2) A $1000 \times$ magnified image of dashed square area in (a-1). (b-2) A 1000 $\times$ magnified image of dashed square area in (b-1). (c-2) SEM image obtained at $5 \mathrm{kV}$ and $3 \mathrm{~A}$ emission current.

The electron beam spot size can be calculated using the SEM images by a method proposed by the American Society for Testing and Materials (ASTM) [42]. The beam spot size was calculated using the contrast ratio of the sharp edge of the mesh line in Figure $6(\mathrm{a}-2, \mathrm{~b}-2)$. The minimum and maximum values were recorded accordingly, and the $20 \%$ and $80 \%$ values were calculated. The distance between $20 \%$ and $80 \%$ was obtained using a commercially available image analysis program. The contrast slopes were 43 and 117 , respectively. Using this, the electron beam spot size (probe size) was calculated as 0.37 and $0.25 \mu \mathrm{m}$, respectively. Relatively large spot size of the electron beam with respect to the virtual source size of $0.8 \mathrm{~nm}$ and $1.3 \mathrm{~nm}$ can be elucidated with the widespread trajectory of electrons by the change of the equivalent potential line near the tip of a CNT cold cathode and the screening effect among emitted electrons. It can be seen that the CNT 
cold cathodes with higher aspect ratios have higher brightness, which in turn leads to images with higher resolution. It has been shown that the structural properties of the CNT electron source eventually lead to differences in resolution.

\section{Conclusions}

We investigated the effect of the structural properties of CNT cold cathodes on the electron beam properties and resolution of secondary electron images. The 1560- CNT cold cathode, with a high $\beta_{\text {geo }}$ and small tip diameter, produced a focused electron beam with high brightness and small beam diameter, consequently allowing us to obtain SEM images of high resolution, compared with the SEM images obtained by the 417-CNT cold cathode with a low $\beta_{\text {geo }}$ and large tip diameter. The theoretical study reveals that the contribution of spreading edge-emitted electrons to the total emission current increases with increasing tip diameter. The simulation results rationally explain the limited image resolution obtained by a SEM system equipped with a 417- CNT cold cathode module. Our results indicate that the geometrical factor of the CNT cold cathode is an important influencing factor to obtain ultra-high-resolution images using secondary electron imaging system.

Author Contributions: Conceptualization, K.C.P.; methodology, K.C.P.; software, H.R.L., B.C.; formal analysis, H.R.L., B.C.; investigation, H.R.L., J.L.; data curation, H.R.L., D.W.K., A.R.; writing—original draft preparation, H.R.L., J.L.; writing-review and editing, K.C.P.; visualization, K.C.P.; supervision, J.L., K.C.P.; project administration, K.C.P.; funding acquisition, K.C.P. All authors have read and agreed to the published version of the manuscript.

Funding: This research received no external funding.

Institutional Review Board Statement: Not applicable.

Informed Consent Statement: Not applicable.

Data Availability Statement: The data presented in this study are available on request from the corresponding author.

Acknowledgments: This work was supported by the Technology Innovation Program (20013595, Extreme ultraviolet light source using nano electron beam) funded by the Ministry of Trade, Industry, and Energy (MOTIE, Korea).

Conflicts of Interest: The authors declare no conflict of interest.

\section{References}

1. Crewe, A.; Eggenberger, D.; Wall, J.; Welter, L. Electron gun using a field emission source. Rev. Sci. Instrum. 1968, 39, 576-583. [CrossRef]

2. De Jonge, N.; Lamy, Y.; Schoots, K.; Oosterkamp, T.H. High brightness electron beam from a multi-walled carbon nanotube. Nature 2002, 420, 393-395. [CrossRef]

3. Zhang, H.; Yuan, J.; Yamauchi, Y.; Suzuki, T.; Shinya, N.; Nakajima, K.; Qin, L. An ultrabright and monochromatic electron point source made of $\mathrm{LaB}_{6}$ nanowire. Nat. Nanotechnol. 2016, 11, 273-279. [CrossRef]

4. Houdellier, F.; Knoopa, L.; Gatela, C.; Masseboeufa, A.; Mamishinb, S.; Taniguchib, Y.; Delmasa, M.; Monthiouxa, M.; Hÿtcha, M.; Snoecka, E. Development of TEM and SEM high brightness electron guns using cold-field emission from a carbon nanotip. Ultramicroscopy 2015, 151, 107-115. [CrossRef]

5. Swanson, L.; Schwind, G. A review of the cold-field electron cathode. Adv. Imaging Electron. Phys. 2009, 159, 63-100.

6. Schwind, G.; Magera, G.; Swanson, L. Comparison of parameters for schottky and cold field emission sources. J. Vac. Sci. Technol. B 2006, 24, 2897-2901. [CrossRef]

7. Intaraprasonk, V.; Xin, H.; Muller, D. Analytic derivation of optimal imaging conditions for incoherent imaging in aberration corrected electron microscopes. Ultramicroscopy 2008, 108, 1454-1466. [CrossRef]

8. Bonard, J.; Salvetat, J.; Stöckli, T.; Heer, W.; Forró, L. Field emission from single-wall carbon nanotube films. Appl. Phys. Lett. 1998, 73, 918. [CrossRef]

9. Gröning, O.; Küttel, O.M.; Emmenegger, C.; Gröning, P.; Schlapbach, L. Field emission properties of carbon nanotubes. J. Vac. Sci. Technol. 2000, 18, 665. [CrossRef]

10. Mann, M.; Gomati, M.; Wells, T.; Milne, W.; Teo, K. The application of carbon nanotube electron sources to the electron microscope. Int. Soc. Opt. Photonics 2008, 7073, 70370.

11. Jonge, N.; van Druten, N. Field emission from individual multiwalled carbon nanotubes prepared in an electron microscope. Ultramicroscopy 2003, 95, 85. [CrossRef] 
12. Filippo, G.; Antonio, B.; Laura, I.; Giuseppe, L.; Francesca, U. Field Emission from Carbon Nanostructures. Appl. Sci. 2018, 8, 526.

13. Clare, C.; Richard, P.; William, M.; Matthew, C. High Performance Field Emitters. Adv. Sci. 2016, 3, 1500318.

14. Peng, Z.; Xiao, Y.; Liang, H.; Zhimeng, H.; Wen, L.; Biao, X.; Xu, X.; Chaojiang, N.; Mengyu, Y.; Liqiang, M. The Young's modulus of high-aspect-ratio carbon/carbon nanotube composite microcantilevers by experimental and modeling validation. Appl. Phys. Lett. 2015, 106, 111908.

15. Minh, D.; Minh, N.; Nguyen, H.; Phan, H.; In, B.; Nguyen, H. Improved Field Emission Properties of Carbon Nanostructures by Laser Surface Engineering. Nanomaterials 2020, 10, 1931.

16. Li, M.; Wang, Q.; Xu, J.; Zhang, J.; Qi, Z.; Zhang, X. Optically Induced Field-Emission Source Based on Aligned Vertical Carbon Nanotube Arrays. Nanomaterials 2021, 11, 1810. [CrossRef]

17. Giubileo, F.; Iemmo, L.; Luongo, G.; Martucciello, N.; Raimondo, M.; Guadagno, L.; Passacantando, M.; Lafdi, K.; Di Bartolomeo, A Transport and field emission properties of buckypapers obtained from aligned carbon nanotubes. J. Mater. Sci. 2017, 52, 6459-6468. [CrossRef]

18. Giubileo, F.; Di Bartolomeo, A.; Scarfato, A.; Iemmo, L.; Bobba, F.; Passacantando, M.; Santucci, S.; Cucolo, M.A. Local probing of the field emission stability of vertically aligned multi-walled carbon nanotubes. Carbon 2009, 47, 1074-1080. [CrossRef]

19. Park, S.; Gupta, A.P.; Yeo, S.J.; Jung, J.; Paik, S.H.; Mativenga, M.; Kim, S.H.; Shin, J.H.; Ahn, J.S.; Ryu, J. Carbon Nanotube Field Emitters Synthesized on Metal Alloy Substrate by PECVD for Customized Compact Field Emission Devices to Be Used in X-Ray Source Applications. Nanomaterials 2018, 8, 378. [CrossRef]

20. Passacantando, M.; Bussolotti, F.; Santucci, S.; Di Bartolomeo, A.; Giubileo, F.; Iemmo, L.; Cucolo, M.A. Field emission from a selected multiwall carbon nanotube. Nanotechnology 2008, 19, 395701. [CrossRef] [PubMed]

21. Bronsgeesta, M.S.; Barth, E.J.; Swanson, L.; Kruit, P. Probe current, probe size, and the practical brightness for probe forming systems. J. Vac. Sci. Technol. B 2008, 26, 3. [CrossRef]

22. Cai, D.; Liu, L. The screening effects of carbon nanotube arrays and its field emission optimum density. AIP Adv. 2013, 3, 122103.

23. Kang, J.; Park, K. Electron extraction electrode for a high-performance electron beam from carbon nanotube cold cathodes. J. Vac. Sci. Technol. B 2017, 35, 02C109. [CrossRef]

24. Park, K.; Ryu, J.; Kim, K.; Yu, Y.; Jang, J. Growth of carbon nanotubes with resist-assisted patterning process. J. Vac. Sci. Technol. B 2007, 25, 1261-1264. [CrossRef]

25. Lee, S.; Kang, J.; Lee, H.; Park, S.; Jang, J.; Park, K. Enhanced and stable electron emission of carbon nanotube emitters with graphitization. Vacuum 2015, 121, 212-216. [CrossRef]

26. Ryu, J.H.; Bae, N.Y.; Oh, H.M.; Zhou, O.; Jang, J.; Park, K.C. Stabilized electron emission from silicon coated carbon nanotubes for a highperformance electron source. J. Vac. Sci. Technol. B 2011, 29, 02b120. [CrossRef]

27. Lee, H.; Kim, D.; Hwang, O.; Cho, B.; Park, K. Scanning electron imaging with vertically aligned carbon nanotube (CNT) based cold cathode electron beam (C-beam). Vacuum 2020, 182, 109696. [CrossRef]

28. Utsumi, Y. Vacuum Microelectronics: What's New and Exciting. IEEE Trans. Electron. Devices 1991, 38, 10. [CrossRef]

29. Munro, E.; Rouse, J.; Liu, H.; Wang, L.; Zhu, X. Simulation software for designing electron and ion beam equipment. Microelectron. Eng. 2006, 83, 994-1002. [CrossRef]

30. Lee, H.; Yang, H.; Park, K. Fabrication of a high-resolution electron beam with a carbon nanotube cold-cathode. J. Vac. Sci. Technol. B 2017, 35, 06G804. [CrossRef]

31. Hawkes, P.; Kasper, E. Emittance. In Principle of Electron Optics II: Applied Geometrical Optics; Academic Press: London, UK, 1996; Chapter 48; pp. 989-998.

32. Jonge, N. Brightness of carbon nanotube electron sources. J. Appl. Phys. 2004, 95, 673. [CrossRef]

33. Urban, R.; Wolkow, R.; Pitters, J. Evaluating Angular Ion Current Density for Atomically Defined Nanotips. Microsc. Microanal. 2014, 20, 1514-1520. [CrossRef] [PubMed]

34. Hainfeld, J. Understanding and using field emission sources. Scan. Electron. Microsc. 1977, 1, 591-605.

35. Vibrans, G. Vacuum voltage breakdown as a thermal instability of the emitting protrusion. J. Appl. Phys. 1964, 35, 2855. [CrossRef]

36. Bonard, J.; Salvetat, J.; Stockli, T.; Forro, L.; Cjatelaom, A. Field emission from carbon nanotubes: Perspectives for applications and clues to the emission mechanism. Appl. Phys. A Mater. Sci. Process. 1999, 69, 245. [CrossRef]

37. Gao, R.; Pan, Z.; Wang, Z. Work function at the tips of multiwalled carbon nanotubes. Appl. Phys. Lett. 2001, 78, 1757. [CrossRef]

38. Hawkes, P.; Kasper, E. Point Cathodes without Space Charge. In Principle of Electron Optics II: Applied Geometrical Optics; Academic Press: London, UK, 1996; Chapter 45; pp. 934-936.

39. Gadzuk, W.; Plummer, W. Field Emission Energy Distribution (FEED). Rev. Mod. Phys. 1973, 45, 487. [CrossRef]

40. Edgcombe, C.; Valdre, U. Microscopy and computational modeling to elucidate the enhancement factor for field electron emitters. J. Microsc. 2001, 203, 188-194. [CrossRef]

41. Kim, J.; Kang, J.; Park, K. Fabrication of Stable Carbon Nanotube Cold Cathode Electron Emitters with Post-Growth Electrical Aging. Micromachines 2018, 9, 648. [CrossRef]

42. ASTM International. Standard Practice for Scanning Electron Microscope Beam Size Characterization. Designation: E 986-04. 2004. Available online: www.astm.org (accessed on 1 June 2017). 